\title{
Operação Urbana Consorciada da Linha Verde: limites e oportunidades à luz da gestão social da valorização da terra*
}

\author{
Linha Verde Urban Operation: limits and opportunities \\ in light of the social management of land value appreciation
}

Paulo Nascimento Neto Tomás Antonio Moreira

\section{Resumo}

Observa-se atualmente o revigoramento dos debates sobre o Estatuto da Cidade, questionando sua efetividade, a baixa participação popular e sua utilização para legitimação de políticas engendradas por interesses particulares. Nesse contexto, este artigo investiga as Operações Urbanas Consorciadas (OU) enquanto mecanismo de recuperação de mais-valias fundiárias. Partindo de um estudo sobre a OU Faria Lima (São Paulo-SP), discute-se de forma prospectiva a OU Linha Verde (Curitiba-PR), em fase inicial de implantação. As análises possibilitam efetuar constatações ao mesmo tempo complementares e contraditórias. Deve-se reconhecer seu potencial na alavancagem da transformação urbana, repartindo os custos da ação pública. Entretanto, evidencia-se sua limitação na gestão social da valorização da terra, carecendo de mecanismos que assegurem o direcionamento adequado dos recursos.

Palavras-chave: operação urbana; mais-valia fundiária; valorização fundiária; Estatuto da Cidade; gestão social da valorização da terra.

\begin{abstract}
Discussions about the City Statute have been resumed, and the questions focus on its effectiveness, poor public participation and its use to legitimize policies guided by private interests. This paper investigates Urban Operations (UO) as a mechanism to recover land surplus value. Based on a study about the Faria Lima UO (city of São Paulo, Southeastern Brazil), the paper discusses the Linha Verde UO (city of Curitiba, Southern Brazil), which is at the initial stage of implementation. The analysis enables to draw conclusions that are both complementary and contradictory. On the one hand, it is necessary to recognize its potential as an important instrument to leverage urban transformation, dividing the costs of public action with stakeholders. However, it is possible to notice its low efficiency in the social management of land value appreciation, as it lacks mechanisms to ensure the appropriate distribution of public resources.
\end{abstract}

Keywords: urban operation; land surplus value; land value appreciation; City Statute; social management of land value appreciation. 


\section{Introdução}

A produção do espaço urbano tem sido objeto de numerosos estudos. Como pano de fundo identifica-se a utilização da cidade enquanto instrumento de acumulação de capital, onde o princípio econômico da busca pelo lucro transforma o solo urbano em valor de troca, os componentes da cidade se convertem em mercadorias - banalmente comercializadas segundo a lei da oferta e da procura - e os proprietários fundiários se apropriam de valores criados pela coletividade por meio da urbanização (Pereira, 2001; Rolnik, Nakano e Cymbalista, 2008).

A tomada de determinadas ações e decisões urbanísticas por parte do poder público - implantação de infraestruturas e equipamentos públicos, mudanças na legislação urbanística e classificação do solo - alavancam a valorização do solo. Destarte, uma ação pública, cujos custos são repartidos por toda a sociedade, resulta em benefícios para poucos proprietários privados. Nesse contexto, os instrumentos de gestão social da valorização da terra adquirem papel fundamental, permitindo ao poder público recuperar mais-valias urbanas, redistribuindo para toda a coletividade a valorização fundiária decorrentes de suas ações (Smolka e Amborski, 2000; Furtado, 2004; Santoro e Cymbalista, 2004).

Avanços significativos nesse campo foram alcançados a partir de 2001, com a aprovação da Lei $n^{\circ}$ 10.257/2001, conhecida por Estatuto da Cidade, que estabelece "normas de ordem pública e interesse social que regulam o uso da propriedade urbana em prol do bem coletivo, da segurança e do bem-estar dos cidadãos, bem como do equilíbrio ambiental " (art. $1^{\circ}$, grifos do autor). Para Piza, Santoro e Cymbalista (2004), a partir do Estatuto da Cidade, consolida-se o entendimento do dever de o Estado promover a justa distribuição dos ônus e benefícios da urbanização entre toda a sociedade, recuperando a valorização resultante de obras públicas de forma a efetivar a função social da propriedade.

Dentre os diversos instrumentos previstos na Lei $10.257 / 2001$, este trabalho concentra sua discussão sobre a Operação Urbana Consorciada, "um dos instrumentos mais polêmicos do Estatuto da Cidade", nas palavras de Santoro e Cymbalista (2008). Conforme conceituam os autores, a Operação Urbana Consorciada (OU) pode ser compreendida como um instrumento de redesenho de determinada parcela do território urbano a partir da alteração de índices urbanísticos e características de uso e ocupação do solo, combinando investimentos públicos e privados (obtidos por meio da outorga onerosa do direito de construir) visando à implementação de um plano urbanístico. Os valores resultantes das contrapartidas são direcionados para uma conta exclusiva de cada operação urbana, a ser utilizado somente para a consecução das intervenções definidas por lei dentro de seu perímetro.

Considera-se Operação Urbana Consorciada o conjunto de intervenções e medidas coordenadas pelo Poder Público municipal, com a participação dos proprietários, moradores, usuários e investidores privados, com o objetivo de alcançar em uma área transformações urbanísticas estruturais, melhorias sociais e a valorização ambiental. (Brasil, 2001, art. 32, § $1^{\circ}$ ) 
Tendo em vista que os instrumentos da política urbana devem seguir todas as diretrizes delineadas no Estatuto da Cidade ${ }^{1}$ (Santoro e Cymbalista, 2004 ), e, portanto, possibilitar a gestão social da valorização da terra, interessa-nos, neste artigo, investigar o alcance da Operação Urbana Consorciada enquanto mecanismo de recuperação de mais-valias fundiárias urbanas.

A recuperação da mais valia [das operações urbanas] advém da aplicação dos instrumentos legais, dos recursos advindos da valorização imobiliária e fundiária resultante da ação do Poder Público e de sua aplicação em obras de infraestrutura urbana, sistema viário necessário ao transporte coletivo, recuperação ambiental e habitação de interesse social, entre outros. (Alvim, Abascal e Moraes, 2011, p. 219 )

Os proprietários que se beneficiarem com a utilização maior do potencial construtivo e, pois, da infraestrutura urbana deverão devolver parte da riqueza gerada à coletividade. (Santoro e Cymbalista, 2008, p. 88)

As operações, segundo seus defensores [ ... ] Permitem que os beneficiários de uma obra paguem seus custos, liberando os recursos públicos para aplicação em investimentos prioritários; Possibilitam a recuperação da chamada "mais-valia urbana", capturando parte da valorização decorrente de um investimento público para que esta não seja apropriada unicamente pelos proprietários e promotores imobiliários. (Fix, 2004, p. 186)

No Brasil, sua aplicação remonta ao início da década de 1990, pioneiramente adotado pelo município de São Paulo. Porém, diversos problemas de implementação foram enfrentados devido à fragilidade da operacionalização na época, conduzindo a uma série de questionamentos pelos órgãos de fiscalização e controle (Sepe e Pereira, 2011).

Com a entrada em vigor do Estatuto da Cidade, em 2001, um conjunto de regras gerais foi estabelecido para as Operações Urbanas Consorciadas, garantindo segurança jurídica para sua aplicação pelos governos municipais. A referida lei previu a figura dos Certificados de Potencial Adicional de Construção (Cepacs): ${ }^{2}$ títulos imobiliários a serem emitidos pelo município, funcionando como mecanismo de venda (alienados em leilão ou utilizados diretamente em obras necessárias à própria operação) de contrapartida relativa à outorga onerosa do direito de construir.

Conforme expõe Maricato e Ferreira (2002), a partir dos Cepacs, o poder público define um estoque de potencial construtivo adicional para a operação urbana, lançando títulos equivalentes no mercado financeiro, de forma a arrecadar antecipadamente os valores referentes à outorga onerosa do direto de construir. Para Alvim, Abascal e Moraes (2011, p. 220), "trata-se de um avanço da política urbana, ao instituir um valor imobiliário capaz de agilizar os investimentos no perímetro das operações urbanas".

Em âmbito nacional, verificam-se até 0 momento apenas duas experiências de Operações Urbanas Consorciadas com emissão de Cepacs implementadas (ambas em São Paulo - OU Faria Lima e OU Água Espraiada) e outra em fase de implementação (OU Porto Maravilha - Rio de Janeiro). Face ao reduzido número de casos existentes no Brasil, pode-se afirmar que a adoção desse mecanismo de engenharia financeira ainda constitui um 
aprendizado em curso no país, cujos descompassos e contradições devem ser compreendidos a fim de mitigá-los quando da constituição de novas operações urbanas.

Nesse contexto, destaca-se a aprovação da Operação Urbana Linha Verde em Curitiba (Lei n. 13.909/2011/Decreto n. 133/2012), a quarta no país com emissão de Cepacs. Caracterizada como a maior operação urbana brasileira (com oferta de 4.475 .000 metros quadrados de área adicional de construção), sua implementação ainda é muito recente, sendo seu decreto regulamentador sancionado apenas em 26 de janeiro de 2012.

Tendo em vista o exposto, busca-se neste artigo debater de modo prospectivo os limites e potencialidades da Operação Urbana (OU) Linha Verde frente às experiências implementadas no cenário brasileiro, com vistas a contribuir para o aprofundamento da discussão das operações urbanas consorciadas enquanto instrumento de gestão social da valorização da terra. Para tanto, impuseram-se as seguintes questões-problema: quais são os principais elementos estruturantes da OU Linha Verde? Esses elementos dificultam ou fomentam a recuperação de mais-valias fundiárias urbanas?

Este artigo está organizado dentro de três grandes seções: inicialmente se discutem questões de ordem metodológica; na sequência se procede à análise da Operação Urbana Faria Lima, em São Paulo (SP) e da Operação Urbana Linha Verde, em Curitiba (PR), e, por fim, discutem-se as potencialidades e deficiências da OU Linha Verde ante a gestão social da valorização da terra.

\section{Metodologia de pesquisa}

Buscando atingir os objetivos propostos, adotou-se a pesquisa bibliográfica e documental como método de pesquisa, organizada segundo um conjunto de processos empregados na investigação, vinculados a procedimentos intelectuais e técnicos realizados segundo planejamento cuidadoso e embasados a partir de reflexões conceituais sólidas (Silva e Menezes, 2001; Gil, 2002). Dentro desse contexto, esta pesquisa se estrutura a partir de três fases complementares, a saber:

Fase 1- Esta primeira fase, de caráter exploratório, buscou o aprofundamento teórico-conceitual com a temática, da qual resultou um estudo bibliométrico inicial, identificando as principais publicações ligadas à temática. Complementarmente, foram inventariados estudos e relatórios técnicos sobre as experiências brasileiras de implementação de Operações Urbanas Consorciadas com emissão de Certificados de Potencial Adicional de Construção (Cepacs), de forma a compreender o panorama nacional de implementação do referido instrumento. Para sua elaboração utilizou-se como técnica de pesquisa a Análise Bibliográfica e Documental, apresentando como resultados o item Universo e Amostra de Pesquisa.

Fase 2 - Esta fase, de caráter descritivo, relaciona-se à contextualização da Operação Urbana Faria Lima, tendo por objetivo compreender seu processo de formulação, sua for- ma de implementação, bem com os principais desdobramentos sobre o ambiente construído. Segundo Gil (2002), essa fase procura 
descrever as características de determinado fenômeno, estabelecendo ainda relações entre variáveis identificadas. Adotou-se a Análise Bibliográfica e Documental como técnica de pesquisa, apresentada no item Operação Urbana Faria Lima - São Paulo (SP).

Fase 3 - A fase analítica procede as fases exploratória e descritiva, visto que, conforme afirma Gil (2002), a análise dos fatores que determinam um fenômeno demanda sua prévia identificação e descrição detalhada. Nesse sentido, a Fase 3 busca discutir os limites e potencialidades da implementação da Operação Urbana Linha Verde, tendo por base as discussões teórico-conceituais bem como os impactos da OU Faria Lima, investigadas na fase anterior. Apoiando-se no policy cicle ${ }^{3}$ (ciclo político) descrito por Frey (2000) e discutido por Trevisan e Van Bellen (2008), este artigo concentra-se na análise da primeira fase do ciclo político (formulação), abordando ainda de forma prospectiva e menos profunda a segunda fase (implementação). Seus resultados são apresentados no item $A$ Operação Urbana Linha Verde - Curitiba (PR).

\section{Universo e Amostra de Pesquisa}

A partir da etapa exploratória, identificou-se a existência de quatro operações urbanas consorciadas com emissão de Cepacs (implementadas ou em fase de implementação) no Brasil, as quais constituem o universo de pesquisa deste trabalho: OU Faria Lima (São Paulo-SP), OU Água Espraiada (São Paulo-SP), OU Porto Maravilha (Riode Janeiro-RJ) e OU Linha Verde (Curitiba-PR). Conforme já exposto anteriormente, a OU Linha Verde será objeto de discussão prospectiva deste trabalho.

Buscou-se então elencar uma experiência efetivada no cenário nacional, de forma a estabelecer paralelos comparativos enriquecedores da discussão. Nesse contexto, optou-se por desconsiderar a experiência carioca - OU Porto Maravilha ${ }^{4}$ (Lei municipal $n^{0}$ 101/2009) - tendo em vista seu precoce processo de implementação.

Já em São Paulo, observa-se uma trajetória histórica de aplicação da Operação Urbana Consorciada, cuja previsão legal remonta ao Plano Diretor de 1985 e a implementação ao final da década de 1990. Atualmente encontram-se em vigor quatro operações urbanas - Faria Lima, Água Espraiada, Água Branca e Centro - uma vez que nas duas primeiras há emissão de $\operatorname{Cepacs}^{5}$ (Alvim, Abascal e Moraes, 2011; Sepe e Pereira, 2011).

Entre essas duas Operações Urbanas, definiu-se o estudo de caso na OU Faria Lima, selecionada de forma não-probabilística e intencional, considerando primordialmente dois aspectos: (1) o maior volume de recursos de contrapartidas financeiras envolvido e (2) o fato da emissão de Cepacs ter ocorrido em uma segunda fase de implementação da referida Operação Urbana (pós Estatuto da Cidade), o que permite verificar eventuais modificações engendradas pela alteração na forma de comercialização do potencial construtivo adicional.

Adotar um método não probabilístico envolve o desenvolvimento de uma abordagem qualitativa, entendida segundo Silva e Menezes (2001) como aquela que reconhece um vínculo indissociável entre os dados objetivos e a subjetividade que permeia os 
fenômenos estudados. Considerando que o objetivo principal desta análise é compreender os resultados da implementação da Operação Urbana consorciada no contexto nacional, a escolha pela abordagem qualitativa dentro de uma amostra não probabilística e intencional é considerada adequada.

\section{Operação Urbana Faria Lima - São Paulo (SP): uma análise sintética}

A primeira iniciativa para criação da Operação Urbana (OU) Faria Lima data de 1991, quando da elaboração do Plano Diretor Estratégico municipal. Posteriormente, sob a gestão do prefeito Paulo Maluf, em 1993, a OU foi encaminhada à Câmara Municipal sob forma de projeto de lei, aprovado em 1995 (Sepe e Pereira, 2011).

Instituída pela Lei n. 11.732/1995, a OU Faria Lima tinha por escopo "a melhoria e a valorização ambiental da área de influência definida em função da implantação do sistema viário de interligação da Avenida Brigadeiro Faria Lima e a Avenida Pedroso de Moraes" (art. $1^{\circ}$ ) prevendo, conforme Montandon (2007), a execução de melhorias no sistema viário, desapropriações, produção de habitação de interesse social e aquisição de terrenos para equipamentos sociais. Com uma visão mais crítica, Sandroni (2001, p. 63) assim sintetiza o objetivo da OU Faria Lima:

[...] se trataba de realizar la prolongación de una avenida (sin ninguna prioridad del punto de vista de la circulación y del tránsito), en cuyos terrenos el precio del metro cuadrado se situaba entre los más elevados de São Paulo.

Sua implementação pode ser dividida em duas fases: uma primeira, anterior ao Estatuto da Cidade, e uma segunda, onde foram efetuadas revisões na OU de forma a adaptá-la ao novo marco legal nacional. Na primeira fase, o perímetro da operação urbana foi dividido em Área Diretamente Beneficiada (ADB), referente ao trecho diretamente beneficiado pela prolongação da Av. Faria Lima, e Área Indiretamente Beneficiada (AIB). A aquisição de direitos urbanísticos adicionais ${ }^{6}$ ocorria com a apresentação de projetos de empreendimento pelos proprietários, a partir dos quais a PMSP calculava individualmente a contrapartida a ser paga por cada edificação.

Segundo Alvim, Abascal e Moraes (2011), a captura das contrapartidas se provou um processo excessivamente moroso, onde os empreendimentos se instalavam muito antes da implantação das infraestruturas necessárias. Complementarmente, conforme expõe Sepe e Pereira (2011), o modelo adotado de valoração das contrapartidas apresentava grande instabilidade jurídica, ${ }^{7}$ gerando uma série de questionamentos por parte dos órgãos de fiscalização e controle.

Nesse contexto, após a aprovação do Estatuto da Cidade (Lei 10.257/2001), a Prefeitura de São Paulo optou por rever a OU Faria Li- ma em 2003, alterando a engenharia financeira da outorga onerosa do direito de construir, adotando a lógica do Cepac, em consonância com o marco legal nacional então aprovado. Destarte, a partir da Lei municipal 13.769/04 (alterada pela lei 
13.871/2004), a PMSP iniciou a emissão de Cepacs, realizando leilões na medida em que se fazia necessário a venda de potencial construtivo, evitando a oferta excessiva de títulos bem como o adensamento descontrolado da área de intervenção (Alvim, Abascal e Moraes, 2011).

Conforme descrevem Sepe e Pereira (2011), foi criada uma tabela de conversão de Cepacs em metros quadrados adicionais, com valores distintos para atividades comerciais e residenciais, reduzindo a subjetividade no cálculo da contrapartida financeira. A partir da nova lei criaram-se quatro setores (e 18 subsetores) em substituição às áreas direta e indiretamente beneficiadas, redistribuindo-se o estoque de metros quadrados adicionais restantes $\left(1.281 .908,54 \mathrm{~m}^{2}\right)$, convertidos em 650.000 Cepacs comercializados por um preço mínimo unitário de $\mathrm{R} \$ 1.100,00$.

Segundo dados da SP-Urbanismo (2011), até outubro de 2011, o poder público já havia comercializado, 635.059 Cepacs $(97,7 \%$ do montante total), captando mais de 1,18 biIhões de reais. Destes, 526.684 títulos já foram convertidos em empreendimentos e 110.875 ainda encontram-se em circulação no mercado financeiro (Tabela 1). Dentro desse panorama é necessário ressaltar a recente aprovação pela Câmara Municipal de São Paulo, em 14 de dezembro de 2011, da emissão adicional de 500 mil Cepacs no âmbito da OU Faria Lima, gerando uma receita estimada de dois bilhões de reais. ${ }^{8}$

Tabela 1 - Resumo da distribuiç̧ão de Cepacs

\begin{tabular}{|c|c|c|}
\hline $\begin{array}{c}\text { Distribuição - Autorização } \\
\text { CVM }\end{array}$ & Cepac & R\$ \\
\hline $1^{\text {a }}$ Distribuição - 26/10/2004 & 53.830 & 59.213 .000 \\
\hline 2ª Distribuição - 28/9/2007 & 313.460 & 413.662 .359 \\
\hline 3ª Distribuição - 20/1/2009 & 267.769 & 711.692 .915 \\
\hline Total Distribuições & 635.059 & 1.184.568.274 \\
\hline Colocação Privada - Programa & 2.500 & 4.311 .800 \\
\hline Total colocado & 637.559 & 1.188 .880 .074 \\
\hline Utilizado & $(526.684)$ & --- \\
\hline Em circulação & 110.875 & --- \\
\hline Cepac - Total & 650.000 & --- \\
\hline Cepac - Saldo & 12.441 & --- \\
\hline
\end{tabular}

Fonte: SP-Urbanismo (2011). 
A partir da análise de estudos anteriores sobre a referida operação urbana (Sepe e Pereira, 2011; Sales, 2005; Montandon, 2007; Fix, 2001), evidencia-se uma distribuição desigual dos benefícios decorrentes das intervenções urbanas, ratificando o clássico descompasso entre a matriz teórica de planejamento urbano e a práxis da gestão urbana, conforme extensivamente discutido por Maricato (2000).

Segundo Montandon (2007), a região onde a OU Faria Lima se insere é foco de intervenções sobre o sistema viário há mais de 20 anos, justificadas pela saturação da infraestrutura existente. Com a instalação da operação urbana, houve, na realidade, uma intensificação dos investimentos públicos, sendo os recursos obtidos com as contrapartidas em sua grande maioria absorvidos pelos custos de desapropriações e obras viárias. Sandroni (2001) corrobora com o exposto, afirmando que

En realidad la OU Faria Lima ocurrió en una región de gran dinamismo inmobiliario, que no necesitaba de incentivos especiales para que los agentes realizasen inversiones en el área. Es cierto que la prolongación de la avenida facilito y valorizó las áreas adyacentes, especialmente porque aumentó la accesibilidad. Pero, incluso si estas inversiones en la extensión de la avenida no hubiesen acontecido, la región ya poseía dinamismo propio, corroborado por las 113 propuestas aprobadas hasta ahora. (Ibid., p. 67)

Para Sandroni (2001), a OU Faria Lima, distante de se consolidar como um instrumento de recuperação de mais valia, representou um compromisso do poder público em investir elevado montante de recursos em uma área já infraestruturada. Assim, a implementação da operação urbana contribuiu para o forta- lecimento de um modelo de desenvolvimento urbano excludente, que concentra recursos e oportunidades em áreas restritas da cidade e em favor de grupos seletos de beneficiários (Fix, 2004; Sepe e Pereira, 2011; Sales, 2005; Montandon, 2007). Esse processo, não acompanhado de outros instrumentos de gestão social da valorização da terra, conduziu à acelerada valorização imobiliária ${ }^{9}$ de um setor nobre da cidade, inviabilizando a implantação de habitação de interesse social e a diversificação de uso proposta pela OU (Sales, 2005; Montandon, 2007).

De fato, desde o início da implementação da OU Faria Lima, houve grande adesão do setor imobiliário. É interessante observar que o consumo do estoque se concentrou, entre 1995 e 2004, na Área Indiretamente Beneficiada (AIB) - respondendo por 59,61\% do potencial adicional de construção adquirido - demonstrando a incapacidade da operação urbana em alavancar 0 adensamento ao longo dos novos trechos de prolongamento da Avenida Faria Lima (ADB), onde foi ofertada a maior parcela de potencial adicional (1.250.000 $\mathrm{m}^{2}-56 \%$ do total).

Inserido nessa dinâmica, observa-se uma maior intensidade do interesse imobiliário no bairro Vila Olímpia (AIB), zona tradicionalmente ocupada por habitações unifamiliares de média densidade, onde não foram efetuados investimentos diretos em melhoria, e houve significativa substituição das edificações existentes por edifícios comerciais de elevado gabarito, alto padrão construtivo e pouca diversidade de usos (Sepe e Pereira, 2011; Montandon, 2007). ${ }^{10}$ 
Essas novas centralidades, constituídas por novas torres resultantes da aglutinação de lotes, expõem a contradição das dinâmicas ocorridas nesta região da cidade: são os distritos que tiveram o maior incremento de área construída e que mais perderam população moradora em todo o município. [...] Tal monta de recursos [investimentos públicos diretos] catalisou a atividade imobiliária, mas não obteve êxito urbanístico equivalente, muito menos social. (Montandon, 2007, p. 18)

Para Fix (2004), a OU Faria Lima obteve como principal resultado a gentrificação de um setor já elitizado da cidade, onde a partir de uma "fórmula mágica de parceria", legitima-se um ciclo de investimentos públicos para fins imobiliários, formalmente justificados pela necessidade de financiamento de infraestruturas. Alinhando-se ao posicionamento de Mariana Fix, Montandon (2007) afirma que apesar da segunda fase da Operação Urbana Faria Lima ter apresentando avanços, ainda não conseguiu romper com a lógica capitalista de produção do espaço que combina adensamento construtivo descolado de adensamento populacional, obras viárias com íntima relação a interesses imobiliários e baixo investimento em habitação de interesse social.

Sepe e Pereira (2011) contribuem com a discussão, afirmando que, apenas em 2010 (portanto, após 15 anos do início da OU), iniciou-se a construção de habitação de interesse social, com vistas a atender parcialmente a população residente em ocupações irregulares afetadas pela operação. Dados apresentados pela Apeop (2011) confirmam o panorama delineado, evidenciando a baixa inversão de recursos para habitação social (menos de 10\% dos recursos investidos pela operação urbana, somados os custos com desapropriação).

Tabela 2 - Resumo dos investimentos: OU Faria Lima (valores até setembro de 2010)

\begin{tabular}{l|r|r}
\hline & Valor $-\mathbf{R \$}$ & $\%$ \\
\hline Obras e serviços & $652.119 .770,05$ & 59,5 \\
Taxas de administração (Emurb) & $68.436 .688,13$ & 6,2 \\
Despesas bancárias, CPMF e outros & $2.570 .865,17$ & 0,2 \\
Desapropriação & $145.687 .904,88$ & 13,3 \\
Desapropriação - HIS & $6.985 .039,89$ & 0,6 \\
Habitação de Interesse Social & $99.942 .652,28$ & 9,1 \\
Transporte coletivo & $120.500 .000,00$ & 11,0 \\
Total & $1.096 .242 .920,40$ & 100,0 \\
\hline
\end{tabular}

Fonte: SP-Urbanismo (apud Apeop, 2011). 


\section{A Operação Urbana Linha Verde - Curitiba - PR}

A rodovia federal BR-116 constitui o principal eixo rodoviário brasileiro, conectando longitudinalmente todo o país, com cerca de quatro mil quilômetros de extensão. Em Curitiba, ela corta o município no sentido Norte-Sul, repartindo a cidade em duas porções, o que gerava dificuldades de transposição e um intenso conflito entre o tráfego urbano e de carga (Figura 1a). Segundo Souza (2001), os problemas gerados pelo cruzamento do eixo

Figura 1a - Eixo da BR 116 Malha urbana atual

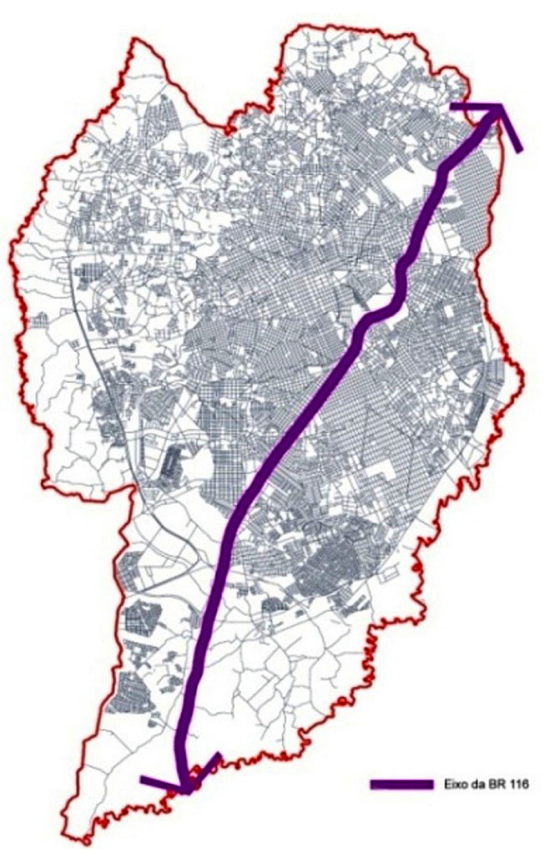

Fonte: adaptado de IPPUC (2011). rodoviário com a malha viária urbana são objetos de preocupação do município desde o Plano Preliminar de Urbanismo de 1965, quando a mancha urbana ainda nem havia ultrapassado a então denominada BR-2 (Figura 1b).

Com a construção do Contorno Leste, projetado com o objetivo de desviar o tráfego de carga do trecho urbano da rodovia, abriu-se ao município a possibilidade de urbanizar um importante eixo de ligação municipal e metropolitano, passando por 23 bairros e estruturando o crescimento da porção leste da cidade (Machuca, 2010).

Figura 1b - Eixo da BR 116 PPU

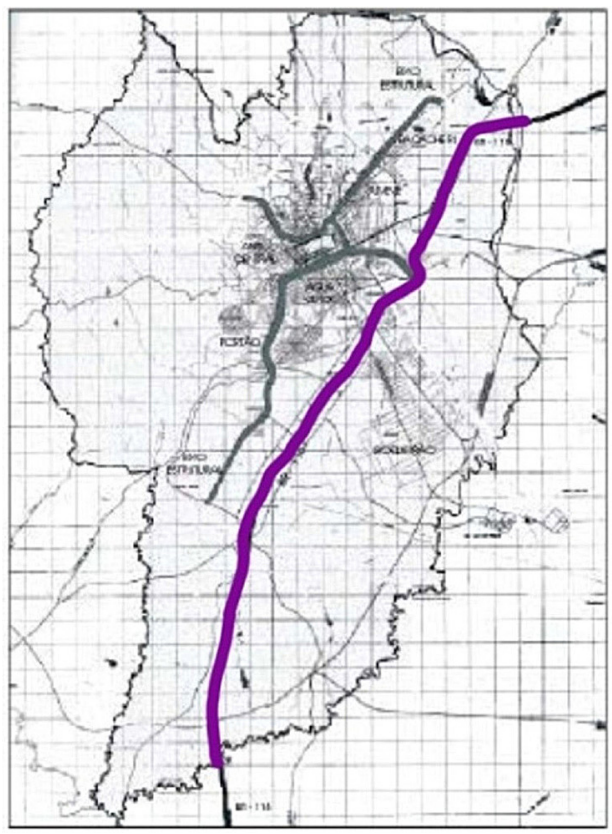

Fonte: adaptado de Souza (2001) 
Apesar das morosas negociações junto ao governo federal para concessão do trecho - que perduraram por mais de uma década o projeto, mesmo com algumas modificações, manteve seu princípio desde o início: construir um eixo de integração intramunicipal e metropolitano, readequando o sistema viário, alterando o uso e ocupação do solo lindeiro (originalmente ocupado por barracões e comér- cios e serviço gerais) e a tipologia de tráfego (Moura, 2011; Hardt, Chu e Hardt, 2009).

Há aproximadamente três décadas, 0 crescimento demográfico [de Curitiba] começou a acelerar-se, tornando necessárias diversas alterações em seu traçado urbano, sendo uma delas - e a mais recente - a transformação do trecho urbano da antiga BR-116 no Eixo Metropolitano, também conhecido como Linha Verde. [...] [A Linha Verde] configura a principal alteração da estrutura urbana, desde a concepção [do planejamento urbano de Curitiba], que data dos anos 1960. (Hardt, Chu e Hardt, 2009, p. 2)

As obras de urbanização, voltadas à adequação do sistema viário e implantação do novo eixo de transporte coletivo, da então denominada Linha Verde (Figura 2a), iniciaram-se em 2007, consumindo $\mathrm{R} \$ 160,9$ milhões apenas no trecho sul (Figura 2b). As alterações no zoneamento, efetuadas no ano $2008,{ }^{11}$ potencializaram a dinâmica imobiliária da área lindeira, que observou variações no custo do metro quadrado superiores a $70 \%$ em alguns locais (Secovi apud Rios, 2009).

Analisado os resultados preliminares destas ações, Machuca (2010), Hardt, Chu e Hardt (2009) identificam uma tendência (ainda que lenta) de transformação no uso e ocupação do solo da região, com gradual substituição das edificações atuais por empreendimentos voltados ao uso residencial e de comércio e serviço local.

Com o objetivo de alavancar a transformação urbana nas áreas lindeiras ao eixo da Linha Verde, a Prefeitura de Curitiba propôs a implementação da Operação Urbana (OU) Linha Verde. ${ }^{12} 0$ projeto de lei, encaminhado a Câmara em outubro de 2011, foi sancionado pelo prefeito Luciano Ducci em dezembro de 2011, dando origem a Lei $n^{0} 13.909 / 2011$, regulamentada pelo Decreto $n^{\circ} 133 / 2012$, de 26 de janeiro de 2012.

Formatada sobre a sistemática de emissão de Cepacs, a OU Linha Verde tem por objetivo captar recursos para complementação das obras de sistema viário e transporte, requalificação urbanística, oferta de espaços de uso público e regularização fundiária (Curitiba, 2011, art. 3), promovendo a ocupação ordenada da região, o atendimento à população em situação de vulnerabilidade, a diversificação de usos (em consonância com o previsto no zoneamento proposto), a melhoria do sistema viário e a qualidade urbanística e ambiental da área de intervenção (Curitiba, 2011, art. 4).

Para tanto, o perímetro da operação urbana foi dividido em três setores (Norte, Central e Sul), por sua vez subdivididos em três subsetores, a saber: (1) Polos (Zona: Polo-LV), onde se prevê ocupação de alta densidade, com verticalização e predominância de comércio e serviços; (2) Área Diretamente Beneficiada (Zona: SE-LV), referente ao eixo de adensamento ao longo da Linha Verde, entre os polos, onde se pretende ocupação de média e alta densidade, com predomínio de uso residencial com verticalização; e (3) Área Indiretamente Beneficiada (demais zonas), relacionando-se 
Figura 2a - Linha Verde - extensão total

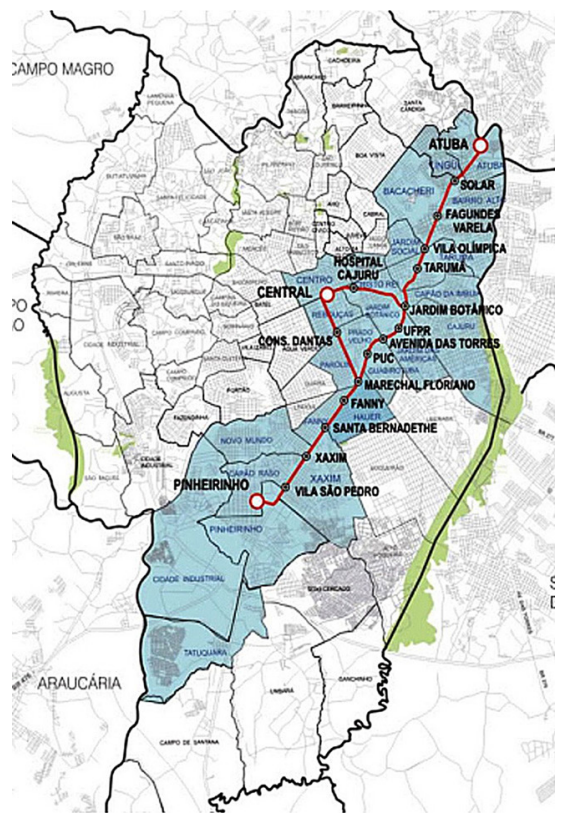

Fonte: IPPUC (2010).

Figura $2 \mathrm{~b}$ - Custo do projeto por trechos

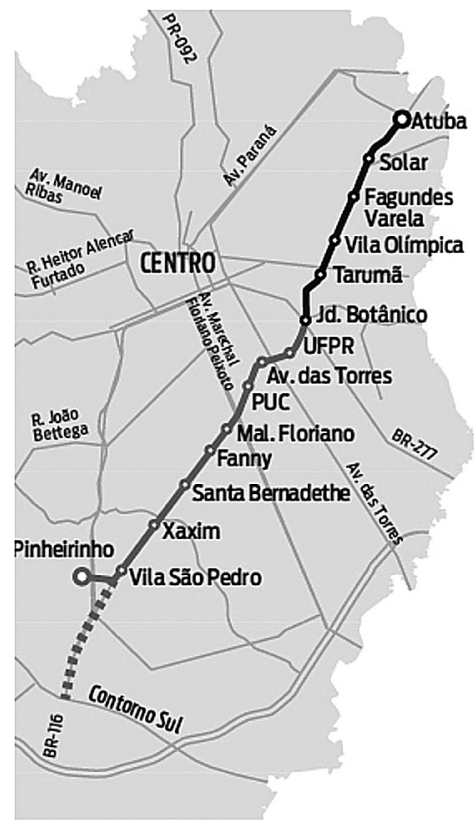

Fonte: adaptado de Cabral (2011)
FASES DO PROJETO

\begin{tabular}{|c|c|c|}
\hline \multirow{6}{*}{$\begin{array}{l}\text { TRECHO NORTE } \\
8 \mathrm{~km} \\
\text { Jardim Botânico - } \\
\text { Atuba }\end{array}$} & Custototal & $\mathrm{R} \$ 198$ milhões \\
\hline & Financiamento & $\begin{array}{l}\mathrm{C}=39,5 \text { milhões ( } \mathrm{R} \$ 86,9 \text { milhões) } \\
\text { garantidos pela Agência Francesa } \\
\text { de Desenvolvimento. Orestante da } \\
\text { verba deve ser ainda captado. }\end{array}$ \\
\hline & Previsãode início & 2007 \\
\hline & Início & 2011 \\
\hline & Previsãodetérmino & 2013 \\
\hline & Estágio atual & Etapa l iniciada \\
\hline \multirow{6}{*}{$\begin{array}{l}\text { TRECHO SUL } \\
9,4 \mathrm{~km} \\
\text { Pinheirinho- } \\
\text { Jardim Botânico }\end{array}$} & Custo inicial & $\mathrm{R} \$ 121,1$ milhōes \\
\hline & Custofinal & R\$160,9 milhões \\
\hline & Financiamento & $\begin{array}{l}\text { Banco Interamericano de } \\
\text { Desenvolvimento (BID) }\end{array}$ \\
\hline & Inicio & Janeiro/2007 \\
\hline & Previsãodetérmino & Março/2008 \\
\hline & Estágio atual & $\begin{array}{l}\text { Falta retirar a passarela em frente } \\
\text { ao Colégio Medianeira. Nas } \\
\text { licitaçőes realizadas para este fim, } \\
\text { não apareceram interessados. }\end{array}$ \\
\hline \multirow{4}{*}{$\begin{array}{l}\text { EXTREMOSUL } \\
3 \mathrm{~km} \\
\text { Pinheirinho-Anel do } \\
\text { Contorno Rodoviário }\end{array}$} & Custo inicial & $\mathrm{R} \$ 61$ milhões \\
\hline & Financiamento & União/PAC da Copa \\
\hline & Previsãode início & 2010 \\
\hline & Estágioatual & Etapal (ver abaixo) \\
\hline
\end{tabular}


as demais áreas contempladas pela OU, onde, em linhas gerais, prevê-se uma zona de amenização do impacto de uso e ocupação do solo, com média densidade, verticalização limitada e predominância de uso residencial. ${ }^{13}$

A OU Linha Verde estabelece uma oferta total de $4.475 .000 \mathrm{~m}^{2}$ de área adicional de construção (repartido de forma desigual entre os setores e usos pretendidos, conforme Tabela 3), a ser convertida em até 4.830 .000 Cepacs, com valor mínimo de venda de $\mathrm{R} \$ 200,00^{14}$ (Curitiba, 2011, art. 13 e 14).

Um ponto polêmico da Operação Urbana Linha Verde se refere ao seu desenho institucional de gestão. Sobre esse aspecto, permite-se efetuar questionamentos sobre dois elementos, considerados fundamentais na discussão da operação urbana enquanto instrumento de gestão social da valorização da terra.

0 primeiro se refere à elaboração do projeto urbanístico, do plano de prioridade de obras e do Estudo de Impacto de Vizinhança da Operação Urbana. Conforme prevê o Plano Diretor Municipal de Curitiba (Lei 11.266 12004), em consonância com o disposto no Estatuto da Cidade (Lei 10.257/2001), são elementos mínimos da lei que aprovar operações urbanas consorciadas: (1) definição da área de abrangência da intervenção; (2) finalidade da operação proposta; (3) programas básicos de ocupação da área e de intervenções previstas; (4) estudo prévio de impacto de vizinhança; (5) programa de atendimento econômico e social para a população diretamente afetada pela operação; (6) contrapartida a ser exigida dos proprietários, usuários permanentes e investidores privados em função da utilização dos benefícios previstos; (7) forma de controle da operação, obrigatoriamente compartilhado com representação da sociedade civil (Curitiba, 2004, art. 7; grifos do autor).

Nesse contexto, a Lei $n^{0}$ 13.909/2011, que aprovou a Operação Urbana Linha Verde, relegou a elaboração do Plano de Prioridade de Intervenções (art. 19 ), do Plano e Projeto urbanístico (art. 20) e do Estudo de Impacto Ambiental (EIA/Rima) a uma etapa posterior, contradizendo-se ao disposto na Lei Municipal 11.266/04 (Plano Diretor Municipal de Curitiba), que supostamente deveria regê-lo. Complementarmente, apesar do programa de atendimento econômico e social ser mencionado enquanto um dos objetivos gerais da OU Linha Verde, não são previstos mecanismos para efetivá-lo nem mesmo definem-se quais os elementos mínimos que o compõem.

Tabela 3 - Área adicional de construção (ACA), segundo setores

\begin{tabular}{l|c|c|c|c|c}
\hline \multirow{2}{*}{ Setor } & \multicolumn{5}{|c}{ Área adicional de construção $\left(\mathbf{m}^{2}\right)$} \\
\cline { 2 - 5 } & Total & \multicolumn{2}{c}{ Uso residencial } & \multicolumn{2}{c}{ Uso não residencial } \\
\hline Norte & 1.280 .000 & 960.000 & $75 \%$ & 320.000 & 25 \\
Central & 1.275 .000 & 765.000 & $60 \%$ & 510.000 & 40 \\
Sul & 1.920 .000 & 1.535 .000 & $80 \%$ & 385.000 & 20 \\
Total & 4.475 .000 & 3.260 .000 & $73 \%$ & 1.215 .000 & 27 \\
\hline
\end{tabular}

Fonte: Curitiba (2011). 
Distante de se colocar em xeque a capacidade técnica de elaboração desses documentos (em grande parte sobre responsabilidade do Ippuc), questiona-se aqui a inexistência da participação popular no processo de formulação da operação urbana. E, mesmo que esta fosse realizada, de que forma a população poderia avaliar um projeto de intervenção urbana que não possui um plano de ações claramente delineado, onde não há a clara definição dos impactos ambientais, sociais e econômicos envolvidos e suas medidas mitigadoras? ${ }^{15}$

Essa pergunta nos conduz ao segundo questionamento sobre a forma de gestão da Operação Urbana Linha Verde, a saber: a baixa representatividade da sociedade civil no seu processo de implementação. A Lei $n^{\circ}$ 13.909/2011, em seu artigo 18, estabelece um grupo de gestão com vistas ao acompanhamento e implementação do Programa de Intervenções da Operação Urbana Consorciada.

Coordenado pelo Instituto de Pesquisa e Planejamento Urbano de Curitiba (Ippuc), esse grupo é formado por onze integrantes, com a seguinte composição:

a) 1 representante da Secretaria Municipal do Urbanismo - SMU;

b) 1 representante da Secretaria Municipal de Finanças - SMF;

c) 1 representante da Secretaria Municipal de Administração - SMAD;

d) 1 representante da Secretaria Municipal do Meio Ambiente - SMMA;

e) 1 representante da Secretaria do Governo Municipal - SGM;

f) 1 representante do Instituto de Pesquisa e Planejamento Urbano de Curitiba - Ippuc; g) 1 representante da Câmara Municipal de Curitiba;

h) 1 representante do Sindicato da Indústria da Construção Civil no Estado do Paraná - Sinduscon-PR;

i) 1 representante do Sindicato da Habitação e Condomínios do Paraná - Secovi-PR;

j) 1 representante da Associação dos Dirigentes de Empresas do Mercado Imobiliário no Estado do Paraná - Ademi-PR;

k) 1 representante do Conselho da Cidade de Curitiba - Concitiba.

Ao se analisar a composição do Grupo de Gestão, que supostamente contaria com a participação de "entidades representativas da sociedade civil" (Curitiba, 2011, art. 18), evidencia-se uma concentração do poder público municipal $(7-63,4 \%)$ e de entidades relacionadas ao mercado imobiliário (3 - 27,3\%), relegando à sociedade civil apenas uma vaga no grupo de gestão, representada pelo Concitiba.

Agravando esse quadro, ao se ponderar os diversos questionamentos sobre a legiti- midade do Concitiba (Silva et al., 2011; TDD, 2010; CED, 2011), que não segue a proporcio- nalidade entre sociedade civil e poder público estabelecidos pelas legislações estaduais e federais e não possui representatividade significativa de organizações da sociedade civil, torna-se frágil anuir a existência de participação popular no processo de implementação da OU Linha Verde. Complementarmente, é interesse observar a composição da Comissão Executiva do Programa de Intervenções, responsável pela definição do Plano de Prioridades de Intervenções e o Programa de Investimentos da Operação Urbana Consorciada Linha 
Verde. A mesma é formada por seis representantes de órgãos municipais ${ }^{16}$ (os mesmos que compõem o grupo gestor), que, sozinhos, representam mais de $50 \%$ do grupo gestor e, portanto, poderiam, por si só, aprovar por maioria os planos por eles mesmos elaborados. $\mathrm{E}$, ainda que não respondessem pela maior parte dos votos, as negociações dentro do grupo gestor estariam concentradas entre o poder público e as entidades ligadas ao mercado imobiliário, afastando-se da definição das obras aqueles que, supostamente, deveriam ser priorizados pelos recursos obtidos com os Cepacs.

Diante da experiência da OU Faria Lima, discutida no capítulo anterior, e face às simi- laridades com o caso curitibano quanto ao processo de gestão, é forçoso indagar sobre o limitado papel da OU Linha Verde enquanto instrumento de gestão social da valorização da terra. Ao se incluir nesse cenário o intenso lobby engendrado pelo mercado imobiliário (que, inclusive, possui significativa representatividade no grupo gestor) e pelas empreiteiras voltadas à execução de obras públicas, levanta-se a hipótese da OU Linha Verde estar mais próxima a um mecanismo de dinamização do mercado imobiliário do que propriamente de um instrumento de fortalecimento da função social da cidade e da propriedade (conforme prevê o Estatuto da Cidade).

Nesse sentido, Piza, Santoro e Cymbalista (2004) alertam que a implementação de uma operação urbana consorciada sem uma adequada gestão social dos recursos envolvidos conduz incontestavelmente à definição de prioridades "de poucos" em detrimento dos interesses da coletividade, que demoram a se efetivar, ou, sequer se efetivam. Corroborando com o exposto, Alvim, Abascal e Moraes
(2011) afirmam que operações urbanas conduzidas inadequadamente tendem a potencializar os efeitos excludentes da urbanização contemporânea, ao concentrar ações singulares de intervenção que não agregam contribuições reais à coletividade.

A Prefeitura investe com a justificativa de estimular e atrair "capital privado", realizando obras chamadas de "âncora" ou "projeto motor" da operação, por serem capazes de dar início a um processo de renovação urbana mais amplo. Assim, o governo cumpre o papel de uma empresa de desenvolvimento imobiliário, de agente desbloqueador do potencial de negócios de determinada região. (Fix, 2004, p. 187)

Destarte, para Fix (2004), a operação urbana consorciada constitui um mecanismo eficazmente adotado para encobrir a lógica de concentração de renda na cidade, legitimando o direcionamento de vultosos recursos públicos para áreas infraestruturadas e para obras de benefícios restritos, levando o poder público a assumir um papel central na dinamização da acumulação privada (e não da recuperação, como era de se supor) de mais-valias fundiárias urbanas.

\section{Considerações finais}

Há décadas a captura da mais-valia fundiária produzida pelos investimentos públicos é discutida e perseguida no Brasil. Dentre os diversos instrumentos urbanísticos e tributários previstos pelo Estatuto da Cidade, sem dúvidas a Operação Urbana Consorciada figura como um dos mais discutíveis e contraditórios. 
Desde as primeiras experiências de implantação desse instrumento, durante a década de 1990, em São Paulo, observam-se intensos debates sobre as motivações ocultas sobre a nobre argumentação de se buscar a redistribuição da mais-valia fundiária para a coletividade. Ainda que não se possa negar o grande potencial das operações urbanas consorciadas (OU) enquanto mecanismo de alavancagem de transformações urbanas - repartindo os custos decorrentes da ação pública -, a desarticulação (intencional ou meramente imprudente) da OU com outros instrumentos urbanísticos existentes, tende a reduzir seu alcance enquanto mecanismo de gestão social da valorização da terra, gerando conflitos entre os diferentes atores inseridos no perímetro de intervenção, bem como projetos e propostas por vezes descoladas da dimensão técnica. De fato, programas e planos urbanos deslocados de políticas sociais tendem a conformar o substrato básico para a continuidade do clientelismo político, característico da gestão pública brasileira

Partindo do exposto e da constatação de Maricato e Ferreira (2002), para quem "é fartamente admitido que a aplicação ou a interpretação das leis dependem das circunstâncias", pode-se especular sobre o constante predomínio dos interesses de grupos sociais de maior influência, que possuem maior capacidade de lobby sobre as decisões relacionadas à gestão da política urbana municipal.

Nesse contexto, pode-se até mesmo questionar o papel dos Certificados de Potencial Adicional de Construção (Cepac), que, embora permitam ao poder público capturar rápida e antecipadamente os recursos da iniciativa privada, também podem ser entendidos como elementos subordinadores da política urbana ao mercado imobiliário, transformando a outorga onerosa do direito de construir em uma fonte complementar de especulação financeira.

Outro ponto crítico das operações urbanas consorciadas diz respeito à restrição dos investimentos dentro do perímetro de intervenção, entendido por diversos autores como limitadora da função social da propriedade e da cidade, visto que se reinvestem vultosos recursos em áreas infraestruturadas da cidade, alavancando a elevação dos preços da terra e acirrando as desigualdades socioterritoriais intraurbanas.

Apesar das diversas contradições inerentes ao processo de formulação e implementação das operações urbanas consorciadas no Brasil, acredita-se que, caso essas dispusessem de mecanismos consistentes de gestão democrática e participativa, poder-se-ia mitigar os riscos de prevalência de interesses privados sobre a coletividade. Entretanto, contrariando essa constatação, os casos estudados neste trabalho apontam para a baixíssima representatividade da sociedade civil em todo o processo, que sequer é consultada quando da aprovação da OU.

Ainda que os resultados não se provem suficientemente profundos para embasar a defesa de uma hipótese, arrisca-se concluir este artigo especulando sobre a insuficiência das operações urbanas consorciadas, por si só, de promover a gestão social da valorização da 
terra. É necessário salientar que o trabalho desenvolvido tem por objetivo contribuir com as investigações a respeito dos instrumentos de recuperação de mais-valias fundiárias pós
Estatuto da Cidade, agregando subsídios para o aprofundamento da discussão teórica e empírica sobre a questão, sem a pretensão de encerrar os debates sobre a temática.

\section{Paulo Nascimento Neto}

Observatório das Metrópoles - Núcleo Curitiba, projeto de pesquisa Metropolização e Megaeventos, subeixo Moradia e Dinâmica Urbana e Ambiental.Curitiba/PR, Brasil.

paulo.nn@uol.com.br

\section{Tomás Antonio Moreira}

Pontifícia Universidade Católica de Campinas, Programa de Pós-Graduação em Urbanismo, Curso de Arquitetura e Urbanismo. Campinas/SP, Brasil.

tomas.moreira@puc-campinas.edu.br

\section{Notas}

(*) O presente trabalho foi realizado com o apoio da Capes, entidade do Governo Brasileiro voltada para a formação de recursos humanos.

(1) Conforme previsto no artigo 20 da referida lei, todos os instrumentos devem se alinhar as diretrizes da Política Urbana, entre elas a " IX - Justa distribuição dos benefícios e ônus decorrentes do processo de urbanização" e a "XI - recuperação dos investimentos do Poder público de que tenha resultado a valorização de imóveis urbanos.

(2) Os Cepacs são previstos nos artigos 28 a 30 e 32 a 34 da Lei n. 10257/2001.

(3) Conforme expõe Frey (2000), o agir público pode ser dividido em fases parciais do processo político-administrativo de resolução de problemas - formulação, implementação e controle dos impactos - os quais conformam o ciclo político, importante elemento na análise de políticas públicas. Embora a Operação Urbana constitua um instrumento (Piza, Santoro, Cymbalista, 2004) e não propriamente uma política pública, entende-se que esse conceito pode ser aplicado à discussão da implementação do referido instrumento urbanístico sem prejuízos epistemológicos. 
(4) Tendo por objetivo revitalizar uma área historicamente degradada do Rio de Janeiro, prevê alterações nos parâmetros construtivos - viabilizadas por meio da Outorga Onerosa do Direito de Construir via Cepac's -, alcançado coeficiente de aproveitamento igual a 12, gabarito de 50 pavimentos e taxa de ocupação de 100\% em algumas áreas (CDURP, 2011). Apesar da recente emissão dos 6,4 milhões de certificados (integralmente adquiridos pela CEF por R\$3,5 bilhões em junho de 2011), já se observam diversas críticas ao projeto que "tem vendido a ideia de renovação urbana completa, desconsiderando a existência de um local de moradia repleto de relações sociais [...] condenando a realidade destas áreas como indesejável (Bentes et al., 2011, p. 15).

(5) Para informações mais detalhadas sobre cada uma delas, sugerimos consultar o site: www. prefeitura.sp.gov.br/cidade/secretarias/infraestrutura/sp_obras/empresa/index.php?p=22040. (6) O estoque total de potencial construtivo adicional perfazia $2.250 .000 \mathrm{~m}^{2}$.

(7) Para o cálculo da contrapartida era aplicado um deflator, de forma discricionária, sobre o valor estabelecido a partir da análise técnica do grupo de avaliação, fragilizando sua legitimação.

(8) Embora a maioria dos títulos tenha sido negociada, a área construída adicional obtida via Cepac não alcançou os 1,5 milhões de $\mathrm{m}^{2}$ permitidos pela lei (totalizou apenas $692 \mathrm{mil} \mathrm{m}^{2}$ face coeficientes de conversão relativa aos setores da operação urbana), possibilitando a emissão adicional.

(9) Dados da Amaral d’Ávila Egenharia de Avaliações de 2004 (apud Montandon, 2007), demonstram que o valor do metro quadrado de terreno nas áreas de maior adensamento duplicou em todos os setores analisados.

(10) Segundo Montandon (2007), a revisão da OU Faria Lima, em 2004, não implicou em modificações desse padrão, permanecendo inalterada a concentração do interesse imobiliário nas porções externas à área principal de intervenção.

(11) A partir da Lei 12.767 de 2008, estabeleceram-se incentivos construtivos para terrenos situados na área de abrangência do projeto da Linha Verde além de critérios específicos para a outorga onerosa do direito de construir nas zonas polos, SE-BR-116 e ZT-BR-116.

(12) A revisão do Plano Diretor Municipal de Curitiba, realizada em 2004, já contemplava, no artigo 75, a realização de uma Operação Urbana Consorciada no atual eixo da Linha Verde.

(13) O mapa com a delimitação dos setores e usos estabelecidos dentro do perímetro urbano da Operação Urbana da Linha Verde encontra-se disponível em: http://www.curitiba.pr.gov.br/ multimidia/00112770.pdf.

(14) A estimativa inicial de arrecadação de $\mathrm{R} \$ 1,5$ bilhão (Sinduscon, 2011).

(15) Corroborando com esse entendimento, cabe ressaltar que mesmo entre os vereadores, quando da aprovação do projeto de lei, registraram-se debates acirrados envolvendo a inexistência de informações a cerca dos impactos e medidas mitigadoras relacionadas à operação urbana Linha Verde (CMC, 2011).

(16) Subordinada ao Grupo Gestor, a Comissão Executiva é formada unicamente por representantes dos órgãos municipais e possui a seguinte composição: a) 1 representante da Secretaria Municipal do Urbanismo - SMU; b) 1 representante da Secretaria Municipal de Finanças - SMF; c) 1 representante da Secretaria Municipal de Administração - SMAD; d) 1 representante da Secretaria Municipal do Meio Ambiente -SMMA; e) 1 representante da Secretaria do Governo Municipal - SGM; f) 1 representante do Instituto de Pesquisa e Planejamento Urbano de Curitiba - Ippuc. 


\section{Referências}

ALVIM, A. A. T. B.; ABASCAL, E. H. S. e MORAES, L. G. S. de (2011). Projeto Urbano e operação urbana consorciada em São Paulo: limites, desafios e perspectivas. Cadernos Metrópole, v. 13, n. 25, pp. 213-233.

AN INTER-AMERICAN COMPARISON (2000). Cambridge, Lincoln Institute of Land Policy.

ASSOCIAÇÃO PAULISTA DE EMPRESÁRIOS DE OBRAS PÚBLICAS (APEOP) (2011). Quadro de acompanhamento OUC Faria Lima. Disponível em: http://www.apeop.org.br/ arquivos/diversos/ op_urbanas2610.pdf>. Acesso em: dez 2011.

BENTES, J. C. da G.; LEAL, L. P.; COSTA, M. S. da e SILVA, P. S. da (2011). Perspectivas de transformação da região portuária do Rio de Janeiro e a Habitação de interesse social. In: XIV ENCONTRO NACIONAL DA ANPUR. Anais. Rio de Janeiro, Anpur.

BRASIL (2001). Lei no 10.257 de 10 de Julho. Estabelece diretrizes gerais da política urbana. Brasília, Diário Oficial da União.

CABRAL, T. (2001). Linha Verde ao preço de duas. Gazeta do Povo, Vida e Cidadania, 3 de agosto, sem página. Disponível em: http://www.gazetadopovo.com.br/vidaecidadania/conteudo. phtml?id=1153722. Acesso em: dez 2011.

CÂMARA MUNICIPAL DE CURITIBA (CMC) (2011). Operação Consorciada Linha Verde recebe aval. Notícia, 16 de dezembro. Disponível em: http://www.cmc.pr.gov.br/ ass_det.php?not=18136. Acesso em: dez 2011.

CIDADE EM DEBATE (CED) (2011). Em busca da justiça social. Disponível em: http://www. cidadeemdebate.net/index.php/textoseartigos/64-artigos/222-embuscadajusticaso cial?start=1/. Acesso em: dez 2011.

COMPANHIA DE DESENVOLVIMENTO URBANO DA REGIÃO DO PORTO DO RIO DE JANEIRO (CDURP). Projeto Porto Maravilha. Disponível em: http://www.portomaravilha.com.br. Acesso em: dez 2011.

(2010). Estudo de Viabilidade - Operação Urbana Consorciada da Região do Porto do Rio de Janeiro (OUCPRJ). Rio de Janeiro: CDURP. Disponível em: http://www.portomaravilha.com.br/ web/esq/estudos.aspx. Acesso em: dez 2011.

CURITIBA (2004). Lei Municipal 11.266/2004 - Dispõe sobre a adequação do Plano Diretor de Curitiba ao Estatuto da Cidade. Curitiba, Diário Oficial Municipal.

(2011). Lei Municipal 13.909/2011 - Aprova a Operação Urbana Consorciada Linha Verde e estabelece diretrizes urbanísticas para a área de influência da atual Linha Verde (...). Curitiba, Diário Oficial Municipal.

CYMBALISTA, R. e SANTORO, P. F. (2006). A Outorga Onerosa do Direito de Construir no Brasil: entre a regulação e a arrecadação. In: SEMINÁRIO POLÍTICA FUNDIÁRIA MUNICIPAL E GESTÃO SOCIAL DA VALORIZAÇÃO DA TERRA. Anais. São Paulo, Instituto Pólis/Fundação Getúlio Vargas.

FIX, M. (2001). Parceiros da exclusão. Duas histórias da construção de uma "nova cidade" em São Paulo: Faria Lima e Água Espraiada. São Paulo, Boitempo.

(2004). “A fórmula mágica da parceria público-privada: Operações Urbanas em São Paulo”. In: SCHICCHI, M. C. e BENFATTI, D. (orgs.). Urbanismo: dossiê São Paulo - Rio de Janeiro. Campinas, PUCCAMP/PROURB, pp. 185-198. 
FREY, K. (2000). Políticas públicas: um debate conceitual e reflexões referentes à prática da análise de políticas públicas no Brasil. Revista Planejamento e Políticas Públicas, n. 21, pp. 211-259.

FURTADO, F. (2004). "Recuperação de mais-valias fundiárias urbanas: reunindo os conceitos envolvidos". In: SANTORO, P. (org.). Gestão social da valorização da terra. São Paulo, Instituto Pólis.

GIL, A. C. (2002). Como elaborar projetos de pesquisa. São Paulo, Atlas.

HARDT, C.; CHU, G. D. e HARDT, L. P. A. (2009). A "Linha Verde" no processo de gestão do território: o caso do eixo metropolitano de Curitiba. In: XIII ENCONTRO NACIONAL DA ANPUR. Anais. Florianópolis, Anpur.

INSTITUTO DE PESQUISA E PLANEJAMENTO URBANO DE CURITIBA (IPPUC). (2010). Ficha técnica de projetos urbanísticos. Disponível em: http://www.ippuc.org.br/ippucweb/sasi/home/. Acesso em: dez 2011.

MACHUCA, M. N. (2010). Operações urbanas consorciadas como instrumento de gestão urbana: as experiências de Belo Horizonte, São Paulo e Curitiba. Dissertação de mestrado. Curitiba, Pontifícia Universidade Católica do Paraná.

MARICATO, E. (2000). "As ideias fora do lugar e o lugar fora das ideias". In: ARANTES, O.; VAINER, C. e MARICATO, E. A Cidade do pensamento único: desmanchando consensos. Petrópolis, Vozes.

MARICATO, E. e FERREIRA, J. S. W. (2002). “Operação Urbana Consorciada: diversificação urbanística participativa ou aprofundamento da desigualdade?” In: OSÓRIO, L. M. (org.). Estatuto da Cidade e Reforma Urbana: novas perspectivas para as cidades brasileiras. Porto Alegre, Sergio Antonio Fabris.

MONTANDON, D. T. (2007). Estudo da Operação Urbana Faria Lima: avaliação crítica e novos rumos. In: XII ENCONTRO NACIONAL DA ANPUR. Anais. Pará, Anpur.

MOURA, R. (2011). Grandes projetos urbanos e planejamento territorial. Boletim Campineiro de Geografia, v. 1, n. 1., pp. 7-30.

OLBERTZ, K. (2011). Proposta de Desenvolvimento urbano em Curitiba: o projeto da Operação Urbana Linha Verde. Informativo Justen, Pereira, Oliveira e Talamini, n. 57. Disponível em: http://www. justen.com.br/informativo. Acesso em: dez 2011.

PEREIRA, G. (2001). A natureza (dos) nos fatos urbanos: produção do espaço e degradação ambiental. Desenvolvimento e Meio Ambiente, n. 3, pp. 33-51.

PIZA, M. L.; SANTORO, P. e CYMBALISTA, R. (2004). “Estatuto da cidade: uma leitura sobre a perspectiva da recuperação da valorização fundiária". In: SANTORO, P. (org.). Gestão social da valorização da terra. São Paulo, Instituto Pólis.

RIOS, C. (2009). Linha Verde vive onda imobiliária. Gazeta do Povo, Vida e Cidadania, 2 de novembro, sem página. Disponível em: http://www.gazetadopovo.com.br/economia/conteudo. phtml?id=940161. Acesso em: dez 2011.

ROLNIK, R.; NAKANO, K. e CYMBALISTA, R. (2008). "Urban land and social housing in Brazil: the issue of land. In: Participatory Master Plans: the challenges of democratic management in Brazil: the right of the city. São Paulo, Instituto Pólis/Fundação Ford.

SALES, P. M. R. de (2005). Operações Urbanas em São Paulo: crítica, plano e projetos. Parte 2 - Operação Urbana Faria Lima: relatório de avaliação crítica. Vitruvius (arquitextos), n. 059.12, ano 5. Disponível em: http://vitruvius.com.br/revistas/read/arquitextos/05.059/481. Acesso em: dez 2011. 
SANDRONI, P. (2001). "Plusvalías urbanas en Brasil: creación, recuperación y apropiación en la ciudad de São Paulo". In: SMOLKA, M. e FURTADO, F. Recuperación de plusvalías en America Latina alternativas para el desarrollo urbano. Chile, Eure.

SANTORO, P. e CYMBALISTA, R. (2004). "Introdução à expressão "gestão social da valorização da terra". In: SANTORO, P. (org.). Gestão social da valorização da terra. São Paulo, Instituto Pólis.

(2008). "Gestão social da valorização da terra". In: CARVALHO, C. S.; GOUVÊA, D. e BALBIM, R. (coords.). Acesso à terra urbanizada: implementação de planos diretores e regularização fundiária. Brasília, Ministério das Cidades.

SÃO PAULO URBANISMO (SP-URBANISMO) (2011). Operação Urbana Faria Lima - Histórico de Leilões de CEPACs. Disponível em: http://www.prefeitura.sp.gov.br/cidade/secretarias/upload/ desenvolvimento_urbano/sp_urbanismo/FARIA_LIMA/OUCFariaLima31out11_HistoricoLeiloes. pdf. Acesso em: dez 2011.

SEPE, P. M. e PEREIRA, H. M. S. B. (2011). Operações urbanas e as perspectivas de transformação urbanística ambiental no município de São Paulo. In: XIV ENCONTRO NACIONAL DA ANPUR. Anais. Rio de Janeiro, Anpur.

SILVA, E. L. e MENEZES, E. M. (2001). Metodologia de Pesquisa e Elaboração de Dissertação. Florianópolis, Laboratório de Ensino a Distância da UFSC.

SILVA, J. M.; BRAGA, A. L. C.; METZNER, C.; FOWLER, M. B.; ALHER, A.; SUTIL, E. de N. e ANTEZANA, L. do R. C. (2011). Em busca da justiça territorial: encontros e desencontros da política Urbana de Curitiba. In: XIV ENCONTRO NACIONAL DA ANPUR. Anais. Rio de Janeiro, Anpur.

SMOLKA, M. O. e AMBORSKI, D. (2000). Value capture for urban development: an inter-american comparison. Cambrigde, Lincoln Institute of Land Policy.

SOUZA, N. R. de (2001). Planejamento urbano em Curitiba: saber técnico, classificação dos citadinos e partilha da cidade. Rev. Sociol. Polít., n. 16, pp. 107-122.

TERRA DE DIREITOS (TDD) (2010). Biblioteca-notícia: carta de reivindicação será encaminhada ao poder público. Disponível em: http://terradedireitos.org.br/biblioteca/participantes-de-audienciapublica-sobre-impactos-das-obras-da-copa-de-2014-divulgam-carta-de-reivindicacao-que-seraencaminhada-ao-poder-publico/. Acesso em: dez 2011.

TREVISAN, A. P. e VAN BELLEN, H. M. (2008). Avaliação de políticas públicas: uma revisão teórica de um campo em construção. Revista de Administração Pública, v. 42, n. 3, pp. 529-550.

Texto recebido em 24/abr/2013

Texto aprovado em 7/maio/2013 
